\title{
Progressive renal failure in surgically treated hyperparathyroidism
}

\author{
JANE DIXON,* JF SMITH \\ From the *Department of Pathology, John Radcliffe Hospital, Headington, Oxford and the \\ Department of Morbid Anatomy, School of Medicine, University College, London
}

SUMMARY Of 570 patients operated on for hyperparathyroidism, 18 subsequently died (between on day and $12 \mathrm{yr}$ after operation). Pathological findings at necropsy in these patients have been reviewed $\omega_{\perp}$ Four necropsies on patients with untreated hyperparathyroidism have also been reviewed for. comparison. Of these 22 cases, 14 had renal failure at the time of death. This was attributed to the्छ following: nephrocalcinosis 6 ; chronic glomerulonephritis 4; analgesic nephropathy 1 ; cystinuria $1 \%$ sarcoidosis 1 ; and polycystic disease 1 . Of those with renal failure due to nephrocalcinosis, three hadP persistent hypercalcaemia after operation; the other three survived only for a short time. There was no evidence of residual nephrocalcinosis producing progressive renal failure if the plasma calciun $\stackrel{\leftarrow}{\leftarrow}$ concentration was corrected. In those with chronic glomerulonephritis, cystinuria, and polycystiछ disease, the hyperparathyroidism was considered to be tertiary to the renal disease but renal failure was not always present at the time of diagnosis.

There is clinical evidence that successful surgical treatment for primary hyperparathyroidism may be followed by a deterioration of renal function and hypertension despite the restoration of plasma calcium concentrations to normal. ${ }^{12}$ The reasons for this are not clear. The roles of residual nephrocalcinosis, renal calculi, or possibly hypercalcaemic tubular damage unrelated to the deposition of calcium salts have not been fully elucidated. In some cases of hyperparathyroidism, renal disease is the cause rather than the result of parathormone hypersecretion. If this hypersecretion is appropriate in that it results from an attempt to compensate for hypocalcaemia by hyperplasia of the parathyroid glands, the condition is known as secondary hyperparathyroidism $;^{3}$ if it subsequently becomes autonomous due to the development of an adenoma in one gland it is called tertiary hyperparathyroidism. ${ }^{45}$ Hence failure to prevent deterioration of renal function by parathyroid surgery may reflect tertiary rather than primary parathyroid disease.

To investigate the roles of nephrocalcinosis, renal calculi, hypercalcaemic tubular damage, and other renal pathology in the renal failure of treated hyperparathyroidism, a review was made of all patients who had undergone parathyroid surgery and later come to necropsy at University College

Accepted for publication 17 December 1980
Hospital (UCH) between 1959 and 1978. Necropsies carried out in the same period on patients witlip hyperparathyroidism who had not had surgery, were also reviewed for comparison.

\section{Material and methods}

Between 1 January 1959 and 31 December 1978 nec용 ropsies were done on 22 cases of primary and tertiary hyperparathyroidism. Of these, 18 had been operate $\$$. on at UCH at periods varying from one day to 125 years before death. Of the four not operated on, one had severe renal failure at the time of admission, one carcinomatosis, one motor neurone disease, and ong long-standing cystinuria.

Post-mortem tissues were fixed in buffered for malin and paraffin sections examined with haematoxylin and eosin, EVG, periodic acid-Schiff and in certain cases von Kossa's and phosphotungstiê acid-haematoxylin stains. Renal biopsies had not been performed in life on any of the cases.

\section{Results}

The major pathological findings in all cases are recorded in Table 1 together with the period of survival after parathyroid surgery (post-op survival) $\overrightarrow{\mathbb{D}}$ The case numbers in brackets are those in the $\mathrm{UCH}$ series of operated hyperparathyroid patients 
Table 1 Major pathological findings in all cases

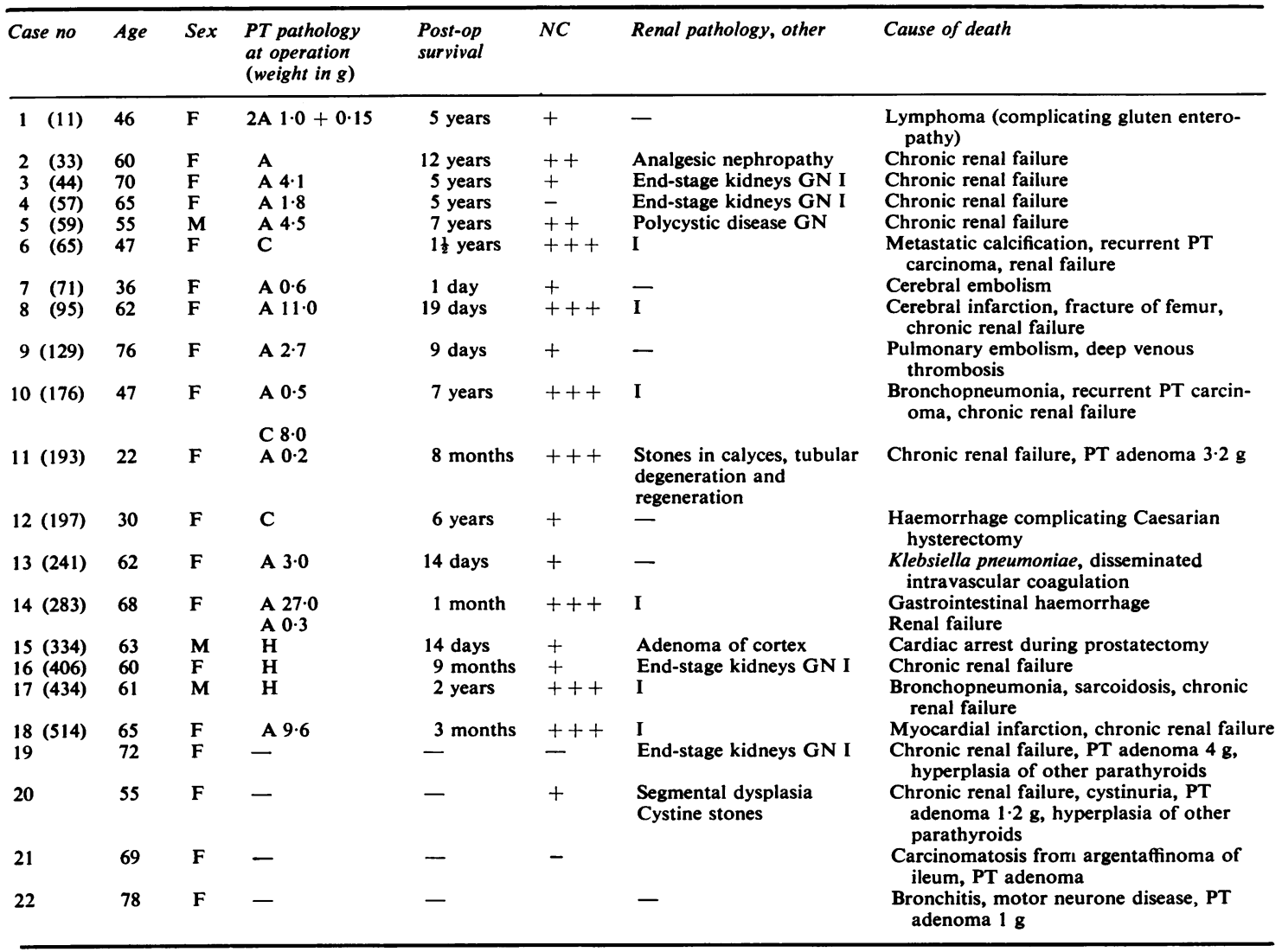

A $=$ Adenoma. $\mathbf{C}=$ Carcinoma. GN $=$ Glomerulonephritis. $\mathbf{I}=$ Ischaemia. $\mathrm{NC}=$ Nephrocalcinosis. $\mathbf{H}=$ Hyperplasia. $\mathrm{PT}=$ Parathyroid.

Nephrocalcinosis was graded on a scale 0 to +++ . This table shows that 14 of the 22 cases had renal failure at the time of death. These could be subdivided into those in which nephrocalcinosis was thought to be the major cause of renal damage (summarised in Table 2) and those in which nephrocalcinosis was thought to play only a minor role (summarised in Table 3). Case 17 was excluded from further analysis as much of the renal damage was thought to be due to hypercalcaemia after long-standing sarcoidosis, together with ischaemic changes. It is possible that some was due to coexistent hyperparathyroidism, but it is impossible to unravel the various factors in this case.

Of the cases without renal failure two died without parathyroid surgery $(21,22)$ and three died shortly after operation $(7,9,13)$. The remaining two $(1,12)$ survived five and six years respectively after parathyroid surgery and, while both showed evidence of mild residual nephrocalcinosis, neither had significant impairment of renal function either preoperatively or terminally.

CASES WITH NEPHROCALCINOSIS CONTRIBUTING TO RENAL FAILURE (TABLE 2)

Of the six cases with renal failure related to nephrocalcinosis three had severe hypercalcaemia at the time of death. This was due to recurrent parathyroid carcinoma in two $(6,10)$ and to a residual adenoma in one (11). In the remaining three cases $(8,14,18)$ hypercalcaemia was no longer present at death but the interval between operation and death was shortnineteen days, one month and three months respectively, and evidence of impaired renal function was present preoperatively. It is also worthy of note that the parathyroid adenomas of these three cases had the largest recorded weights of all those in the present study (11 g, $27 \mathrm{~g}$, and $9.6 \mathrm{~g}$ respectively).

In all these cases the nephrocalcinosis was graded as +++ . At sites of deposition, which were mainly 
Table 2 Cases with nephrocalcinosis contributing to renal failure

\begin{tabular}{|c|c|c|c|c|c|c|c|c|}
\hline \multirow[t]{2}{*}{ Case no } & \multirow{2}{*}{$\begin{array}{l}\text { Post-op } \\
\text { survival }\end{array}$} & \multirow{2}{*}{$\begin{array}{l}\text { PT pathology } \\
\text { (weighting) }\end{array}$} & \multirow[t]{2}{*}{ Blood pressure } & \multicolumn{2}{|c|}{ Plasma Ca (mmolln) } & \multicolumn{2}{|c|}{ Plasma urea $(\mathrm{mmol} / \mathrm{l})$} & \multirow{2}{*}{$\begin{array}{l}\text { Cause of post-op hypercalcaen } \\
\text { if present }\end{array}$} \\
\hline & & & & Pre-op & Terminal & Pre-op & Terminal & \\
\hline 6 & $1 \frac{1}{2}$ years & $\mathbf{C}$ & $\frac{120}{80}$ & $5 \cdot 0$ & $4 \cdot 1$ & 18 & $8 \cdot 3$ & Recurrent PT carcinoma \\
\hline 8 & 19 days & A $11 \cdot 0$ & $\frac{110}{80}$ & $3 \cdot 1$ & $1 \cdot 7$ & 18 & 33 & - \\
\hline 10 & 7 years & $\begin{array}{ll}\text { C } & 0.8 \\
\text { A } & 0.5\end{array}$ & $\frac{140}{90}-\frac{160}{110}$ & $2 \cdot 9$ & $3 \cdot 6$ & $9 \cdot 5$ & $21 \cdot 7$ & Recurrent PT carcinoma \\
\hline 11 & 8 months & A $0 \cdot 2$ & $\frac{110}{70}-\frac{130}{90}$ & $3 \cdot 7$ & 3.9 & 5.7 & 55 & Second PT adenoma $3.2 \mathrm{~g}$ \\
\hline 14 & 1 month & $\begin{array}{l}\text { A } 27 \cdot 0 \\
\text { A } 0.3\end{array}$ & $\frac{140}{90}$ & $3 \cdot 6$ & $2 \cdot 2$ & $13 \cdot 7$ & 25 & - \\
\hline 18 & 3 months & A $9 \cdot 6$ & $\frac{190}{100}$ & $3 \cdot 4$ & $2 \cdot 2$ & $14 \cdot 8$ & $18 \cdot 3$ & - \\
\hline
\end{tabular}

Table 3 Cases of renal failure not primarily due to nephrocalcinosis

\begin{tabular}{|c|c|c|c|c|c|c|c|c|c|}
\hline \multirow{2}{*}{$\begin{array}{l}\text { Case } \\
\text { no }\end{array}$} & \multirow{2}{*}{$\begin{array}{l}\text { Post-op } \\
\text { survival }\end{array}$} & \multirow{2}{*}{\multicolumn{2}{|c|}{$\begin{array}{l}\text { Blood } \\
\text { pressure }\end{array}$}} & \multicolumn{2}{|c|}{ Plasma Ca (mmolll) } & \multicolumn{2}{|c|}{ Plasma urea $(\mathrm{mmol} / \mathrm{l})$} & \multirow[t]{2}{*}{ Cause of renal failure } & \multirow{2}{*}{$\begin{array}{l}\text { Hyperparathy- } \\
\text { roidism }\end{array}$} \\
\hline & & & & Pre-op & Terminal & Pre-op & Terminal & & \\
\hline 2 & 12 years & $\frac{150}{90}-$ & $\frac{210}{145}$ & $3 \cdot 3$ & $2 \cdot 2$ & 5 & 42 & Analgesic nephropathy & Primary \\
\hline 3 & 5 years & $\frac{150}{80}-$ & $\frac{190}{130}$ & $2 \cdot 9$ & 1.9 & 7 & 64 & Chronic glomerulonephritis & Tertiary \\
\hline 4 & 5 years & $\frac{160}{80}-$ & $\frac{200}{120}$ & $2 \cdot 5$ & $2 \cdot 2$ & 10 & 57 & Chronic glomerulonephritis & Tertiary \\
\hline 5 & 7 years & $\frac{140}{90}-$ & $\frac{180}{110}$ & $3 \cdot 2$ & $1 \cdot 4$ & $7 \cdot 5$ & 50 & $\begin{array}{l}\text { Polycystic kidneys, } \\
\text { glomerulonephritis }\end{array}$ & Tertiary \\
\hline 16 & 9 months & $\frac{160}{90}-$ & $\frac{190}{100}$ & $2 \cdot 8$ & $2 \cdot 1$ & $30 \cdot 5$ & $76 \cdot 7$ & Chronic glomerulonephritis & Tertiary \\
\hline 19 & - & $\frac{100}{65}$ & & $2 \cdot 3$ & - & $59 \cdot 7$ & - & Chronic glomerulonephritis & $\begin{array}{l}\text { Secondary or } \\
\text { Tertiary }\end{array}$ \\
\hline 20 & 一 & $\frac{180}{100}-$ & $\frac{250}{150}$ & $3 \cdot 0$ & 一 & $66 \cdot 6$ & - & $\begin{array}{l}\text { Dysplasia of L kidney, } \\
\text { cystinuria }\end{array}$ & Tertiary \\
\hline
\end{tabular}

intraluminal, there was damage to tubular epithelium. Apart from deposits there was some tubular atrophy and dilatation, possibly as a result of blockage of individual nephrons. There were also some areas showing ischaemic atrophy of glomeruli and tubules, maximal in subcapsular zones and associated with severe degenerative arterial disease. Glomerular lesions which could be attributed to a previous nephritis were not present in any of these cases.

Case 11 (193) is described in more detail. A 29year-old negress was investigated because her newborn baby had temporary hyperparathyroidism. She had raised plasma calcium concentrations (3.7 $\mathrm{mmol} / \mathrm{l}$ ), osteitis fibrosa cystica and nephrocalcinosis radiologically. A $0.2 \mathrm{~g}$ adenoma was removed at operation but severe hypercalcaemia persisted. Attempts to lower it with oral phosphate were not successful and she died in renal failure eight months after operation. At necropsy, a further larget adenoma $(3.2 \mathrm{~g})$ was found situated much higher io the neck than usual. Other findings were osteitis fibrosa, a small renal calculus in the calyx of one. kidney and extensive metastatic calcification (Fig. 1N The kidneys were enlarged (R $230 \mathrm{~g}$, L $250 \mathrm{~g}$ ) and showed extensive tubular degeneration and re generacion (Figs. 2 and 3). Neither of these featuress was present in the other patients in Table 2, four \& whose kidneys were significantly reduced in size (less than $100 \mathrm{~g}$ each); in case 6 they were of normang size.

CASES OF RENAL FAILURE NOT PRIMARILY DUE TO NEPHROCALCINOSIS (TABLE 3)

The cases summarised in this table had more sever and prolonged uraemia than those in Table 2. 通 none of the operated cases was hypercalcaemia 


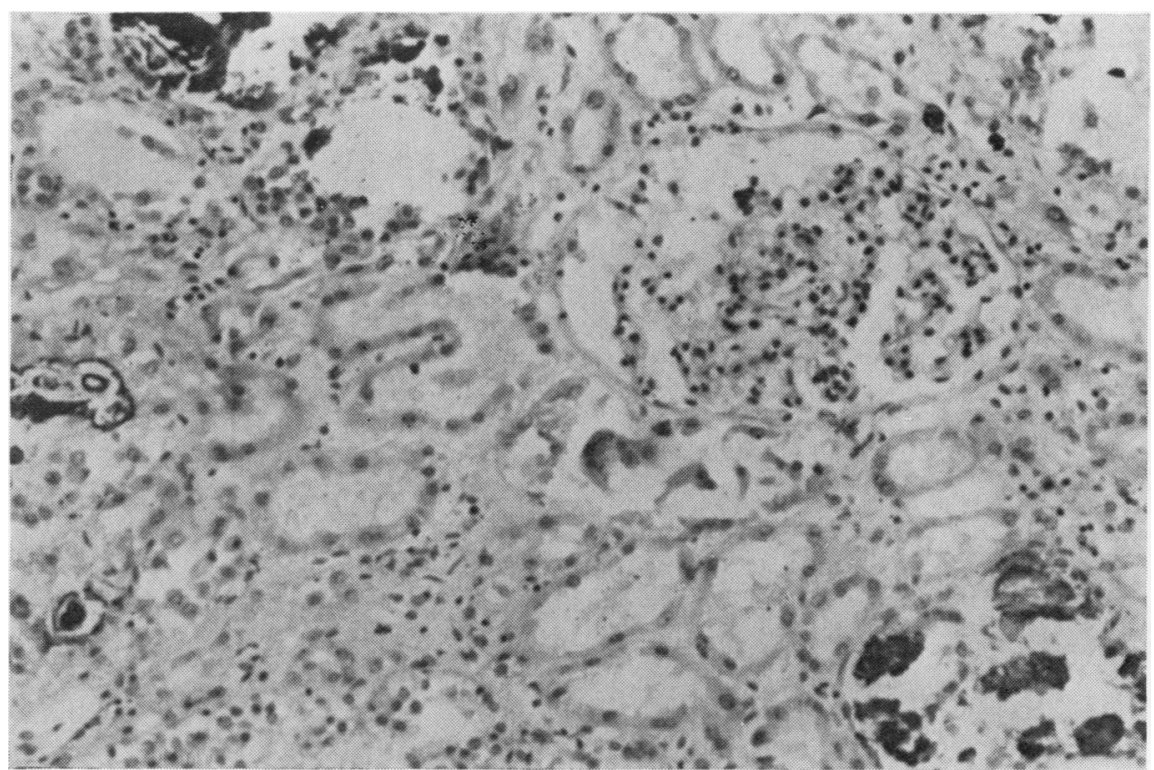

Fig. 1 Case 11

(193) Extensive

metastatic

calcification,

tubular degeneration

and regeneration.

Haematoxylin and

eosin $\times 180$.

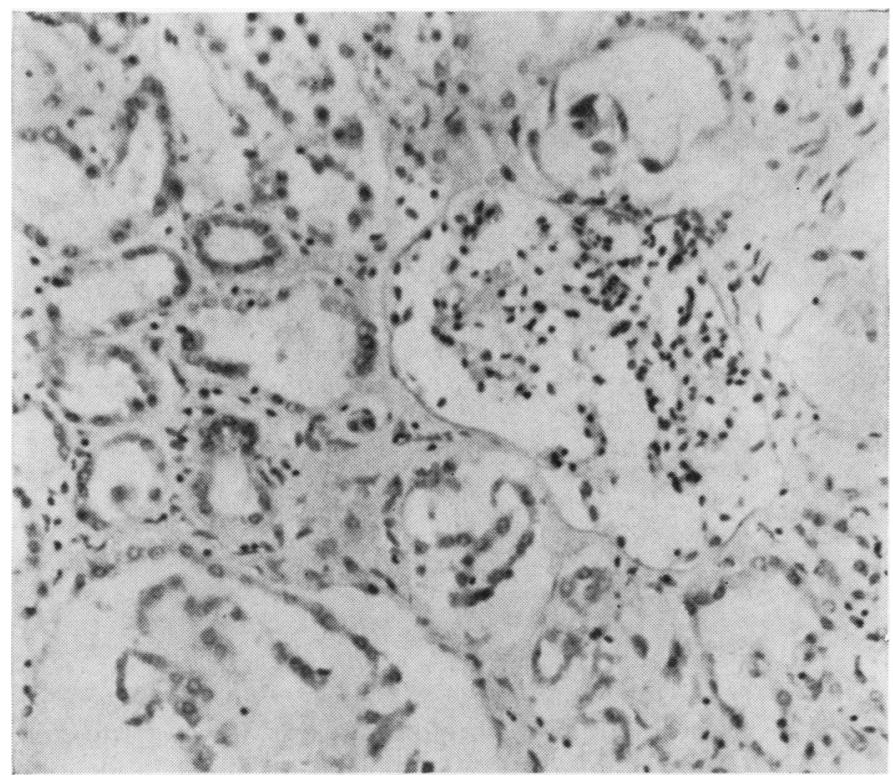

Fig. 2 Case 11 (193) Tubular

degeneration and regeneration.

Haematoxylin and eosin $\times 230$.

present at death. A minor degree of nephrocalcinosis was present in most, comparable with that found in the cases without renal failure. The only cases in this group in which calcification in the kidney was considerable were 2 and 5 . In case 2 the major site of calcification was in necrotic medullary pyramids-a dystrophic calcification rather than a typical nephrocalcinosis, although some of the latter was also present. The cause of the necrosis of the medullary pyramids was excessive consumption of analgesics over a long period and the renal failure occurred long after successful parathyroid surgery. In case 5 there was a moderate degree of nephrocalcinosis in addition to polycystic disease. This is the only case in which residual nephrocalcinosis (some years after successful parathyroid surgery) may have played a part in causing renal failure.

In all the remaining cases in Table 3 renal failure was attributable to lesions other than nephrocalcinosis and these, together with case 5 , were all 


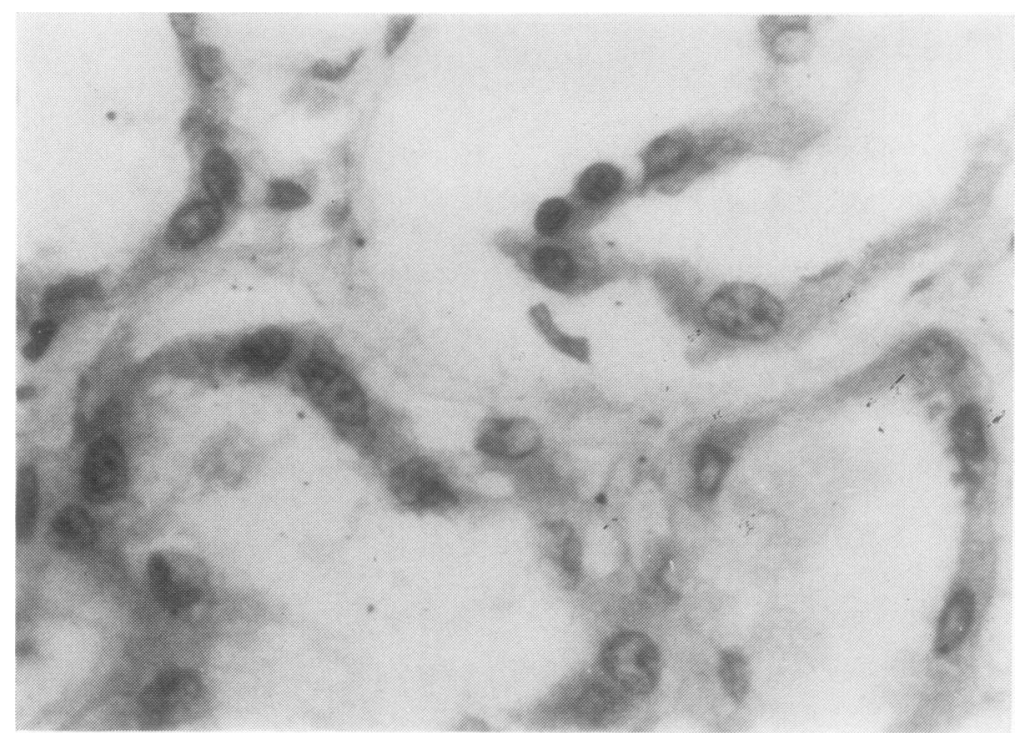

Fig. 3 Case 11 (193) Tubula $\vec{\circ}$ regeneration. Haematoxylin and eosin $\times 920$.

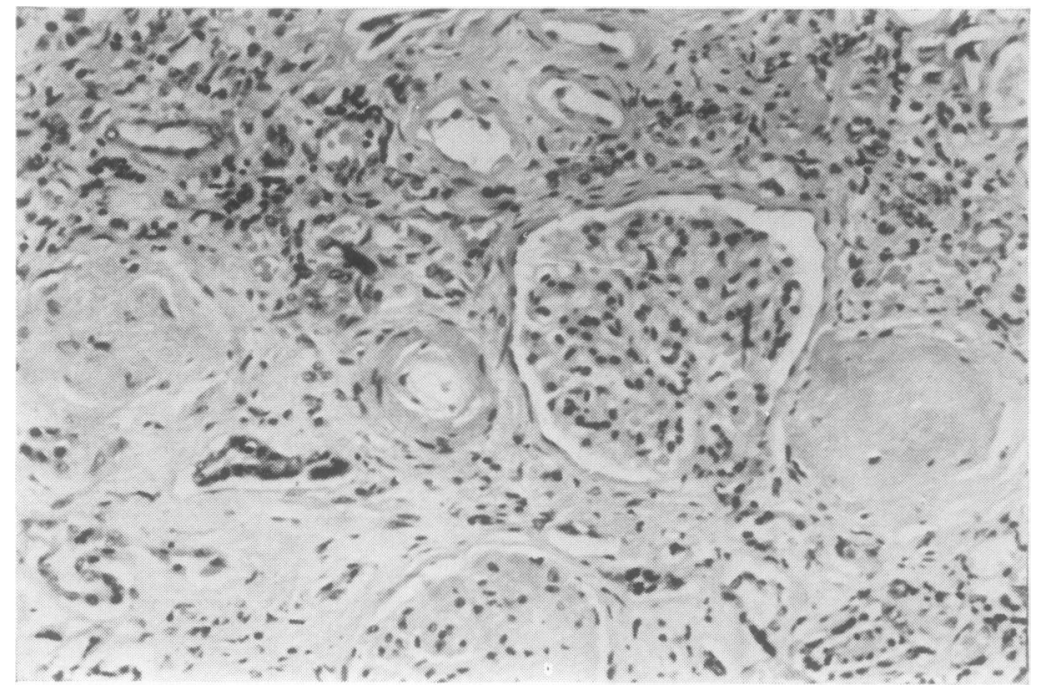

Fig. 4 Case 3 (44) End stage kidney showing hyalinisation of glomeruli from ischaemia and old nephritic lesions. Tubular atrophy and arteriosclerotic vessels also present. Haematoxylin and eosin $x$ 180.

thought to be examples of tertiary hyperparathyroidism (see Discussion).

In four cases there was evidence of progressive glomerular disease. By the time of death all had end-stage kidneys with considerable glomerular loss (Fig. 4). The remaining glomeruli had a variety of lesions including segmental necrosis (Fig. 5), mesangial proliferation and capillary wall thickening (Fig. 6). Adhesions between tufts and capsules were occasionally present. Tubular atrophy and interstitial fibrosis were related to glomerular loss and in all there was severe degenerative disease of intrarenal arteries, but no fibrinoid necrosis. As in many en stage kidneys it was difficult to make a definite diagnosis of the initial process but in most the findings indicated a progressive focal and segmente glomerulonephritis. In case 5, glomerular lesion resembling those described above were present in polycystic kidneys. Two cases $(4,5)$ have previousl been reported in a paper on tertiary hyperparap thyroidism. ${ }^{6}$ Case 3 is now described to illustrate the problem in more detail.

Case 3 (44) This woman was first admitted to UCK 


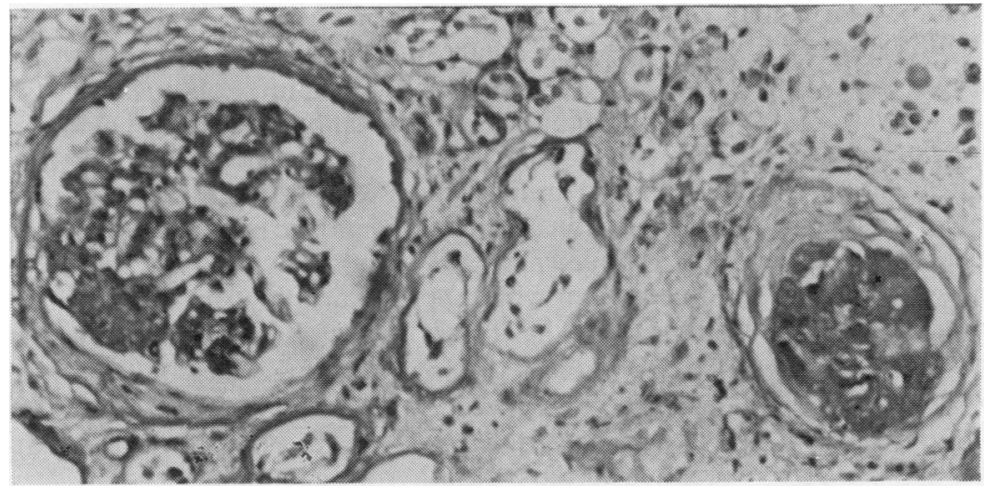

Fig. 5 Case 4 (57) Segmental necrosis in one glomerular tuft. Ischaemic atrophy of another. Periodic acid-Schiff $\times 180$.

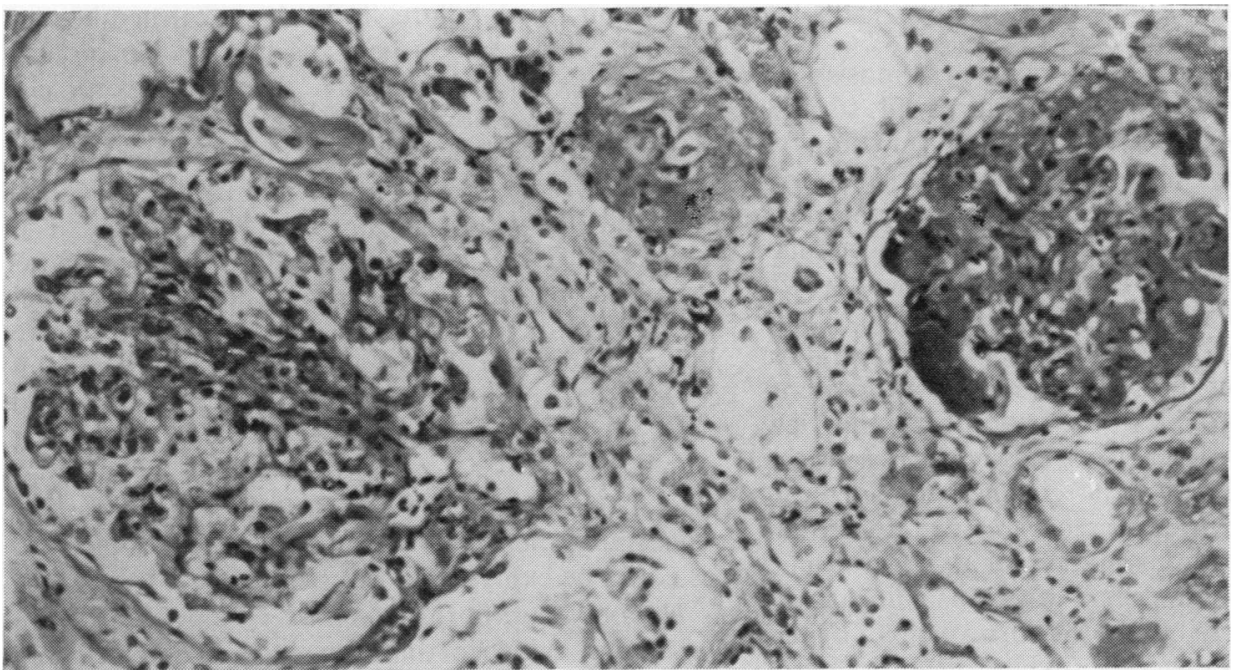

Fig. 6 Case 4

(57) Mesangial proliferation in one glomerular tuft. Increased extracellular matrix in another. Periodic acidSchiff $\times 180$.

in 1959 at the age of 65 with pain in the back, nausea, and vomiting. Radiological evidence showed osteitis fibrosa, hypercalcaemia, a blood urea concentration of $7 \mathrm{mmol} / \mathrm{l}$ and a trace of protein in the urine. She had mild acidosis, thought to be due to renal tubular dysfunction from hyperparathyroidism, but there was no radiological evidence of nephrocalcinosis. A $4.1 \mathrm{~g}$ adenoma was removed from the neck and three normal parathyroids were identified. After operation, her blood urea concentration rose to 23.7 $\mathrm{mmol} / \mathrm{l}$ and was $13.7 \mathrm{mmol} / \mathrm{l}$ on discharge when her acidosis was still present. During the next four years she remained reasonably well but in 1963 she developed pain in the right loin. On examination her blood pressure was 190/130, blood urea concentration $21.0 \mathrm{mmol} / \mathrm{l}$, and her urine contained albumin with only a few red cells, leucocytes, and casts. Symmetrical small kidneys were found on radiography. Her renal failure progressed and she died in 1964 with a blood urea concentration of $64 \mathrm{mmol} / \mathrm{l}$ and plasma calcium concentration of $1.92 \mathrm{mmol} / \mathrm{l}$. At necropsy two mildly hyperplastic parathyroids were identified. The heart was $540 \mathrm{~g}$ with left ventricular hypertrophy and the kidneys uniformly contracted (70 $\mathrm{g}$ each) with granular surfaces, narrowed cortices and normal pelvicalyceal systems. On microscopical examination there was loss of many glomeruli and severe arteriosclerosis. Some glomeruli showed focal, segmental, and other lesions as described above. The considerable tubular atrophy was commensurate with the glomerular disease and nephrocalcinosis was slight. In summary, these were end-stage kidneys in which the vascular element was predominant but with indications of a previous glomerulonephritis.

\section{Discussion}

The results of this survey indicate that an important cause of progressive renal failure after successful 
parathyroid surgery is progressive glomerular and ischaemic disease not associated with stones or extensive nephrocalcinosis. There are three possible explanations for these findings.

The first is that hypercalcaemic damage occurring before surgery in some way initiates glomerular disease which continues even after correction of the plasma calcium concentration. It has been suggested that calcium phosphate deposition within tubules may lead to release of a tubular antigen. This may stimulate antibody formation and subsequently give rise to immune complex deposition within glomeruli. ${ }^{7}$ A second possibility is that glomerular damage is due to irreversible arterial disease initiated by hypercalcaemia. The third, and we believe the most likely explanation, is that hyperparathyroidism in the present cases was tertiary.

The survey indicates that nephrocalcinosis can persist for many years after parathyroid surgery without a significant effect on renal function, as indicated by cases 1 and 12. The degree of nephrocalcinosis in these kidneys did not differ significantly from that in all cases with chronic glomerular disease, except case 5 . This was the only one in which long-standing residual nephrocalcinosis may have been a significant factor in causing renal failure, although two other major factors were also present. Thus the series provides little support for the view that nephrocalcinosis can progress in the absence of hypercalcaemia. There is no evidence that nephrocalcinosis is responsible for progressive glomerular damage. Calcification in glomerular tufts was found in only one case (8) and here it was insignificant.

The second possibility, that irreversible hypercalcaemic-induced arterial disease produces progressive glomerular loss postoperatively, is perhaps less easy to discount. However, some of the glomerular lesions were not typical of those produced by hypertension alone and none of the kidneys showed evidence of malignant hypertension.

The argument against the third possibility, namely that these are cases of tertiary hyperparathyroidism, is that chronic renal failure was not always present at the time of diagnosis of parathyroid disease. This is illustrated by case 3 . Here there was no anatomical evidence of a preceding secondary hyperplasia of parathyroid glands, one adenoma and three normal glands being identified at operation. Similar absence of diffuse parathyroid hyperplasia has been described in a previous paper in 12 cases of tertiary hyperparathyroidism in which parathyroid adenomas were associated with the malabsorption syndrome in 10 and renal disease in two. ${ }^{6}$ It was postulated that in such cases only some groups of sensitive cells within a parathyroid gland respond to a metabolic stimulus, possible hypo- calcaemia, which may be transient or intermittent in character. Cellular division and hormone secretion may subsequently become autonomous. In the absence of either anatomical or biochemical evidence? for a "secondary" phase, the distinction between "primary" and "tertiary" hyperparathyroidism may present considerable diagnostic difficulties. Where $\bar{\sigma}$ mild impairment of renal function is present in association with hyperparathyroidism, the clinicalos importance lies in recognising that renal disease may $\vec{\circ}$ be the initial pathological process and that it is not only the prolonged hypocalcaemia of chronic renalow failure that may provoke formation of a renal related tertiary parathyroid adenoma.

Nephrocalcinosis was significant in this series in $\omega$ producing renal failure if the hypercalcaemia was: not corrected by treatment (as in case 11) or if it. recurred as in cases 6 and 10 where recurrento parathyroid carcinoma was the cause. It played a part in causing renal failure in three cases in which deathe occurred within a few months of parathyroid surgery although in these, extrarenal factors were also $\vec{c}$ important. These three cases had the largest parathyroid adenomas in this series and all had renat impairment before surgery. Previous studies haveo shown that in the absence of renal disease there is a correlation between the weight of a parathyroido adenoma and the degree of hypercalcaemia produced $\frac{\phi}{\circ}$ by it. ${ }^{89} \mathrm{~A}$ similar correlation is difficult to make in these cases because of the complicating factor of $\overrightarrow{\hat{b}}$ renal impair nent, but the severity of nephrocalcino 3 sis could be explained on this basis.

The only case in the present series in whom there. was some evidence that sustained hypercalcaemian had caused extensive renal tubular damage was case11. Severe tubular degeneration and regeneration? were present in sites where deposition of calciums salts was not visible on light microscopy, although there was considerable nephrocalcinosis elsewhere ing both kidneys. Whether or not this tubular damages was related to hypercalcaemia is not certain. It possible that oral phosphate given in an attempt to lower the plasma calcium concentration after unsuccessful surgery may have played a role $\tilde{O}^{-}$ Phosphate-induced tubular damage has beeñ observed in experimental animals. ${ }^{10}$ Clinical im pairment of renal function in man after orad phosphate treatment for hypercalcaemia has beero observed and attributed to exacerbation of nephro ${ }^{+}$ calcinosis. ${ }^{11}$

Renal stones were not significant in the productio of progressive renal failure, except in case 20 where they were of the cystine variety and not due t@ parathyroid disease. This is possibly a reflection of the more successful management in recent decades of 
infection which complicates obstructive disease of the urinary tract.

\section{References}

${ }^{1}$ Britton DC, Thompson MH, Johnston IDA, Fleming LB. Renal function following parathyroid surgery in primary hyperparathyroidism. Lancet 1971 ;ii :74-5.

2 Britton DC, Johnston DA, Thompson MH, Fleming LB. The outcome of treatment and changes in presentation of primary hyperparathyroidism. Br J Surg 1973;60:7825.

${ }^{3}$ Albright F, Reifenstein EC. The parathyroid glands and metabolic bone disease. Baltimore: Williams and Wilkins, 1948.

4 St Goar WT. In: Case records of the Massachusetts General Hospital. Case 29. N Engl J Med 1963;268: 943-53.

${ }^{5}$ Davies DR, Dent CE, Watson L. Tertiary hyperparathyroidism. Br Med J 1968 ;iii:395-9.

- Smith JF. Parathyroid adenomas associated with the malabsorption syndrome and chronic renal disease. $J$ Clin Pathol 1970;23:362-9.

${ }^{7}$ Thier SO. Renal insufficiency and hypercalcaemia. Kidney Int 1978;14:194-200.

${ }^{8}$ Lloyd HM. Primary hyperparathyroidism. An analysis of the role of the parathyroid tumour. Medicine (Baltimore) $1968 ; 47: 53-71$.

' Hodgkinson A. Biochemical aspects of primary hyperparathyroidism: an analysis of 50 cases. Clin Sci 1963; 25:231-42.

${ }^{10}$ Craig JM. Observations on the kidney after phosphate loading in the rat. Archives of Pathology 1959;68:306-15.

11 Dudley FJ, Blackburn CRB. Extraskeletal calcification complicating oral neutral-phosphate therapy. Lancet 1970;ii:628-30.

Requests for reprints to: Dr Jane Dixon, Department of Pathology, John Radcliffe Hospital, Headington, Oxford, England. 